\title{
Comparison of CloudSat and TRMM radar reflectivities
}

\author{
K D Sindhu and G S BhaT* \\ Centre for Atmospheric and Oceanic Sciences, Indian Institute of Science, Bangalore 560 012, India. \\ *Corresponding author.e-mail: bhat@caos.iisc.ernet.in
}

\begin{abstract}
Comparison of reflectivity data of radars onboard CloudSat and TRMM is performed using coincident overpasses. The contoured frequency by altitude diagrams (CFADs) are constructed for two cases: (a) only include collocated vertical profiles that are most likely to be raining and (b) include all collocated profiles along with cloudy pixels falling within a distance of about $50 \mathrm{~km}$ from the centre point of coincidence. Our analysis shows that for both cases, CloudSat underestimates the radar reflectivity by about $10 \mathrm{dBZ}$ compared to that of TRMM radar below $15 \mathrm{~km}$ altitude. The difference is well outside the uncertainty value of $\sim 2 \mathrm{dBZ}$ of each radar. Further, CloudSat reflectivity shows a decreasing trend while that of TRMM radar an increasing trend below $4 \mathrm{~km}$ height. Basically W-band radar that CloudSat flies suffers strong attenuation in precipitating clouds and its reflectivity value rarely exceeds $20 \mathrm{dBZ}$ though its technical specification indicates the upper measurement limit to be $40 \mathrm{dBZ}$. TRMM radar, on the other hand, cannot measure values below $17 \mathrm{dBZ}$. In fact combining data from these two radars seems to give a better overall spatial structure of convective clouds.
\end{abstract}

\section{Introduction}

Tropical deep convective clouds drive the large scale circulation of the tropical atmosphere and play key role in Earth's water and energy cycles (Charney 1969; Holton 2004). Convective clouds present one of the largest sources of uncertainty in weather and climate models (Kerr 2009), and understanding their structure, organization and space-time variation is a frontier area of research in tropical meteorology (Randall et al. 2007). With the objective of measuring various cloud properties at high spatial and temporal resolution round the globe, specialised payloads have been placed on board satellites (King et al. 1992; Wielicki et al. 1996; Kummerow et al. 1998; Diner et al. 1998; Schmetz et al. 2002; Stephens et al. 2002; Winker et al. 2009). Majority of them measure cloud top properties (e.g., outgoing longwave radiation, albedo) or (vertical) integral properties (e.g., cloud liquid water content), i.e., a 2-dimensional (2D) view. Radar is capable of measuring the three dimensional (3D) structure of clouds, however, used to be ground based on weight and power requirement considerations. As a result, radar coverage used to be of limited spatial extent till advancements in technology in the last two decades enabled compact spaceborne radars. In particular, the precipitation radar (PR) on board the TRMM (Tropical Rainfall Measuring Mission) satellite has been providing 3D information concerning tropical clouds since 1998 (Kummerow et al. 1998, 2000). Another satellite, namely CloudSat, with a cloud profiling radar (CPR) on board and launched in 2006 also makes 3D measurements of cloud properties (Stephens et al. 2008). The advantages of these radars are that same sensor measures cloud properties across the globe; continuous efforts have been made by dedicated team of experts to inter-compare

Keywords. CloudSat CPR; TRMM PR; CFADs; radar reflectivity. 
and validate their products, and algorithms and products are updated regularly (e.g., Schumacher and Houze 2000; Stephens et al. 2002; Nicholson et al. 2003a, b; Adeyewa and Nakamura 2003; Wolff et al. 2005; Barker et al. 2008; Hudak et al. 2008; Franchito et al. 2009; Nair et al. 2009; Dinku et al. 2010; Gourley et al. 2010; Kim et al. 2011). As a result, confidence in their products is high.

A large number of studies addressing tropical clouds and cloud systems have been reported using PR data (Masunga and Kummerow 2006; Schumacher and Houze 2006; Casey et al. 2007; Liu and Zipser 2008; Hence and Houze 2011) as well as CPR (Haynes and Stephens 2007; Zhang et al. 2007; Luo et al. 2008; Yuan et al. 2011; Casey et al. 2012; Behrangi et al. 2012). Rajeevan et al. (2012) have examined the vertical structure of Indian monsoon clouds using CloudSat retrieved products. These studies have given emphasis on revealing cloud characteristics such as vertical and spatial extent, cloud microphysics, rainfall estimates, etc., using $3 \mathrm{D}$-information individually provided by $\mathrm{PR}$ and CPR. Very few studies have been carried out using data from both radars. For example, Cetrone and Houze (2009) have studied the differences between maritime, continental and oceanic mesoscale convective systems (MCSs) using PR and CPR data for one monsoon season in 2006-2007. The analysis was carried out employing CFAD (contoured frequency by altitude diagram) of radar reflectivity. They examined MCSs as well as the associated convective and stratiform regions separately using PR data, whereas, for the non-precipitating part of anvil clouds (identified using the criterion CPR reflectivity $<-10 \mathrm{dBZ}$ below $5 \mathrm{~km}$ ) CPR data was used. Below the freezing level, West Africa and Bay of Bengal MCSs are found to have the highest and lowest modal reflectivity among the three cases. In their upper portions, the thick anvils of West Africa MCSs have a broad, flat histogram of reflectivity, while corresponding case over the Bay of Bengal has a sharply peaked distribution. For thick anvils, the mode of maximum contoured frequency is found at reflectivity $\sim-5 \mathrm{dBZ}$ at $9 \mathrm{~km}$ for Bay of Bengal while for West Africa it occurs at $\sim 0 \mathrm{dBZ}$ at $8 \mathrm{~km}$. It may be noted that the work of Cetrone and Houze (2009) does not provide a case to compare the two reflectivity products. A study by Yuan et al. (2011) has also delineated the differences in CFADs of continental and oceanic regions. $\mathrm{Li}$ and Schumacher (2011) have examined the anvil clouds associated with tropical deep convection, and found that the anvil cloud top heights obtained from PR are underestimated by $\sim 5 \mathrm{~km}$ on average compared to CPR.
A common cloud property measured by a radar is the 'radar reflectivity factor' $(Z)$ defined by (e.g., CIMO 2008),

$$
Z=\frac{\sum_{i} D_{i}^{6}}{V_{p}}=\frac{1024(2 \ln 2)}{10^{(-18)} \pi^{3} c}\left[\frac{\lambda^{2}}{P_{t} \tau G_{o}^{2} \Theta \Phi}\right]\left[\frac{r^{2} \overline{P_{r}}}{|K|^{2}}\right],
$$

where $V_{p}$ is the radar beam volume, $D_{i}$ is the diameter of spherical particles occupying the volume, $c$ is the speed of light, $\lambda$ is the radar beam wavelength, $P_{t}$ is the transmitted power, $G_{o}$ is the radar gain, $K$ is the dielectric constant of water, $r$ is the range (distance between antenna and target), $\Theta$ and $\Phi$ are the radar beam widths along two axes normal to the beam propagation direction and $\tau$ is the radar pulse duration. Few key assumptions are made while deriving equation (1), important ones being (i) beam intensity attenuation caused by the atmospheric constituents (gaseous and hydrometeors when present) is negligible, and (ii) scattering by cloud drops/droplets is Rayleigh (CIMO 2008). When attenuation is not negligible, corrections are applied while $Z$ is given out as a product (Iguchi and Meneghini 1994; Testud et al. 2000; Gorgucci and Chandrasekar 2005). The definition of $Z$ accounts for differences in $\lambda$, antenna characteristics, transmitted power, distance of target from source, hydrometeor type, etc. Sampled volume may contain liquid, ice, melting ice particles or mixture of these depending on the conditions inside the cloud. In ordinary radar measurements, the numbers of particles, composition and shape are not known and an equivalent reflectivity factor $Z_{\mathrm{e}}$ is defined assuming the backscattering particles are spherical water drops (Houze 1993). For single polarized radars, $Z_{\mathrm{e}}$ is given as a product, and it is implicitly understood that it is a cloud property, in particular, a measure of the amount of condensed water per unit volume (Houze 1993). This forms the basis of the reflectivity-rainfall $(Z-R)$ relationships which do not explicitly include radar characteristics.

One of the products of PR and CPR is $Z_{\mathrm{e}}$. These two radars work at different wavelengths, their sensitivities, dynamic range and sampling volumes differ (table 1). Scattering and attenuation characteristics of the radar beam are sensitive to the wavelength (CIMO 2008) and thus $\lambda$ has a bearing on $Z$ itself. Therefore, it is important to understand how $Z_{\mathrm{e}}$ from PR and CPR compare with each other. To our knowledge a study that compares PR and CPR reflectivities is not available in the public domain and this study is aimed at filling the gap by using coincident (collocated and near simultaneous) data from both satellites. Our study shows that there are significant differences in the vertical structure of $Z_{\mathrm{e}}$ measured by these two radars. 
Table 1. Summary of CloudSat radar and TRMM precipitation radar characteristics.

\begin{tabular}{lcl}
\hline Characteristics & CloudSat $C P R$ & TRMM $P R$ \\
\hline Frequency & $94 \mathrm{GHz}$ & $13.8 \mathrm{GHz}$ \\
Pulse width & $3.3 \mu \mathrm{sec}$ & $1.6 \mu \mathrm{sec}$ \\
Pulse repetition frequency & $4300 \mathrm{~Hz}$ & $2776 \mathrm{~Hz}$ \\
Minimum detectable signal & $-29 \mathrm{dBZ}$ & $17(18)^{*} \mathrm{dBZ}$ \\
Dynamic range & $\sim 70 \mathrm{dBZ}$ & $\geq 70 \mathrm{dBZ}$ \\
Vertical resolution & $240 \mathrm{~m}$ & $250 \mathrm{~m}$ \\
Cross-track foot print & $1.4 \mathrm{~km}$ & $4.3(5.0)^{*} \mathrm{~km}$ \\
Along-track foot print & $2.5 \mathrm{~km}$ & $4.3(5.0)^{*} \mathrm{~km}$ \\
Swath width & $1.4 \mathrm{~km}$ & $217(247)^{*} \mathrm{~km}$ \\
\hline
\end{tabular}

*: Numbers inside the brackets correspond to post TRMM satellite orbit height increase in August 2001.

$Z_{\mathrm{e}}$ values from $\mathrm{PR}$ are consistently higher than that of CPR. In particular, CPR $Z_{\mathrm{e}}$ suffers strong attenuation below $6 \mathrm{~km}$ height (thus underestimates the cloud hydrometeor amount), whereas, $\mathrm{PR}$ underestimates the vertical extent of deep convective clouds. PR and CPR seem to complement each other with each individually measuring in the range where the other is not. Therefore, the more complete information on the structure of cloud system emerges if data from PR and CPR are seen together wherever possible.

\section{Data and methods}

\subsection{Radar reflectivity data}

$Z_{\mathrm{e}}$ (expressed in dBZ units) from TRMM-PR and CPR has been used in this study. It is important to note the differences between PR and CPR characteristics (table 1 ). $\mathrm{PR}$ is a $\mathrm{Ku}$-band radar having $\lambda \sim 2.2 \mathrm{~cm}$ (frequency $13.8 \mathrm{GHz}$ ). Currently, it is flying in $35^{\circ}$ inclination non-synchronous orbit at an altitude of $402.5 \mathrm{~km}$ after August 2001 (which was $350 \mathrm{~km}$ when launched in 1997). PR footprint size was $4.3 \mathrm{~km}$ at nadir (launch time to August 2001) with 49 ray tracks giving a swath width of $217 \mathrm{~km}$. Footprint size increased to $5.0 \mathrm{~km}$ at nadir and swath width became $247 \mathrm{~km}$ postorbital height change. The vertical resolution is $250 \mathrm{~m}$ at nadir, geographic coverage is from $38^{\circ} \mathrm{S}$ to $38^{\circ} \mathrm{N}$, and it completes about 16 orbits per day. The minimum detectable signal of PR is $\sim 17 \mathrm{dBZ}$ (and $18 \mathrm{dBZ}$ after orbital boost), dynamic range $>70 \mathrm{dBZ}$, and uncertainty $\sim 1.5 \mathrm{dBZ}$ below $0^{\circ} \mathrm{C}$ isotherm and $\sim 2.0 \mathrm{dBZ}$ above $0^{\circ} \mathrm{C}$ isotherm (Kummerow et al. 1998; Steiner and Houze 1998; Kawanishi et al. 2000; Schumacher and Houze 2000). The CPR onboard CloudSat (a member of polar orbiting sun-synchronous satellites of NASA $A$-train constellation at an altitude of $705 \mathrm{~km}$ ) is nadir viewing $W$-band radar with $\lambda=3.2 \mathrm{~mm}$ (frequency $94 \mathrm{GHz}$ ) and launched in April 2006 (Stephens et al. 2008). The minimum detectable signal strength of CloudSat $Z_{\mathrm{e}}$ is $\sim-30 \mathrm{dBZ}$ with a dynamic range of $70 \mathrm{dBZ}$. CPR has a single beam with cross-track and along-track resolutions of 1.4 and $2.5 \mathrm{~km}$, respectively. The vertical resolution is $480 \mathrm{~m}$ oversampled to obtain range gate spacing of $240 \mathrm{~m}$ (Mace et al. 2007; Marchand et al. 2008). The measurement accuracy of CPR is $\sim 1 \mathrm{dBZ}$ (Protat et al. 2011) rather than $2 \mathrm{dBZ}$ claimed earlier (Stephens et al. 2002, 2008).

For a fair comparison, it is important that both satellites measure a given sampling volume near simultaneously. PR and CPR have different swath widths, footprint sizes and orbital trajectories but comparable orbital periods. Because the satellite carrying the former is non-sun-synchronous and that carrying the latter is sun-synchronous, their orbits do intersect approximately 30 times per day. As part of CloudSat project, 2DCloudSat-TRMM Product is made available at www.cloudsat.cira.colostate.edu (a note prepared by Carty and Kuo in 2008 and available at the website gives product details). In this product, an intersect is defined as both TRMM and CloudSat observing the same geographic location on the surface of the Earth with time difference of 50 minutes or less. The intersection of CloudSat path with the midpoint of PR swath is taken as the point of intersection. Many products are listed under $\mathrm{PR}$ and CPR, and this study uses CPR reflectivity product 2B-GEOPROF and PR attenuation corrected reflectivity product TRMM-2A25, both archived under 2D-CloudSat-TRMM dataset. Two data subsets are prepared around the point of intersection. For the PR data,

- PR block data that includes the entire PR swath from 10 scans before and 10 scans beyond the region of intersection,

- PR curtain data, a subset of PR block data containing interpolated PR data along the CloudSat 
track using a simple nearest-neighbour approach to match the CPR horizontal resolution, but no vertical resolution matching is performed. CPR curtain data includes the CPR track data 50
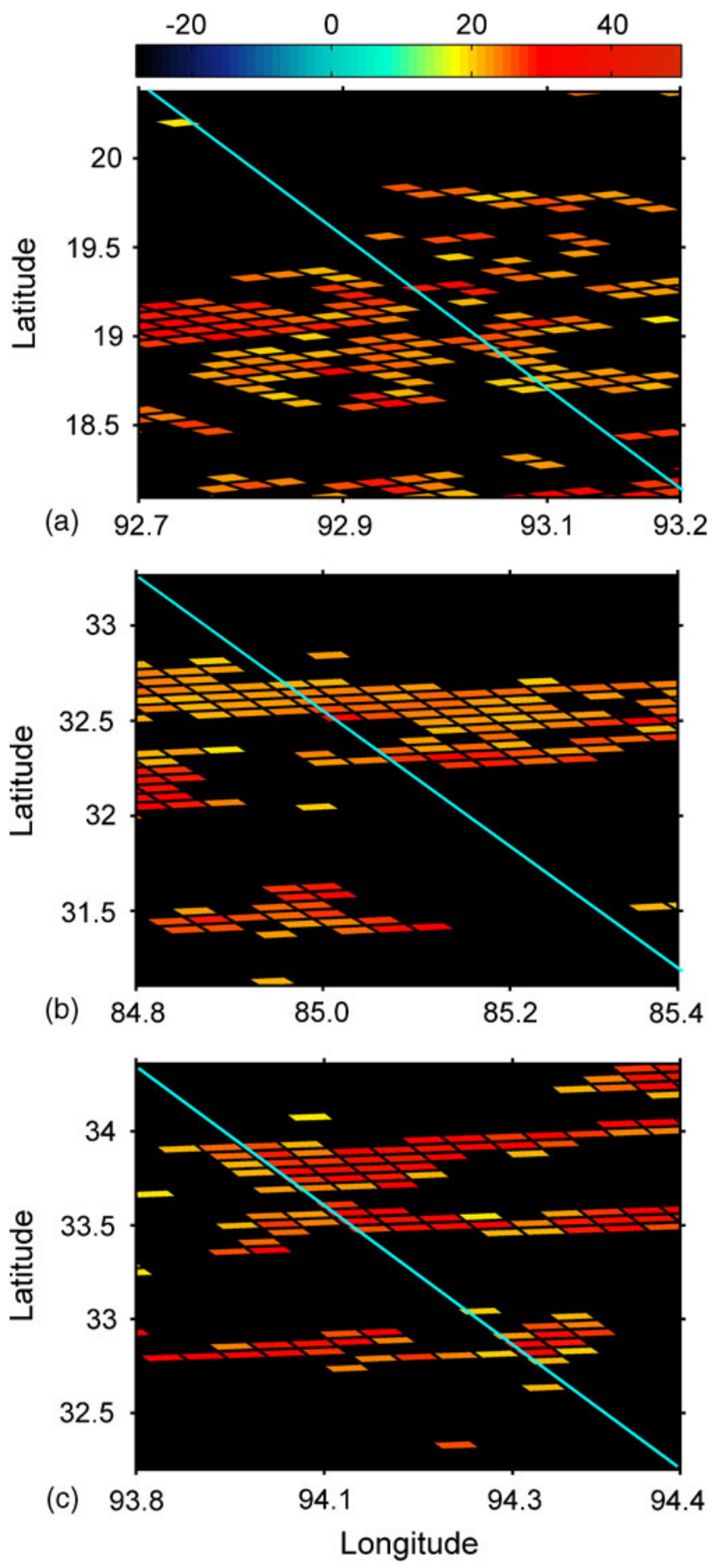

Figure 1. Examples of TRMM PR and CloudSat CPR coincident overpasses observed on 8 July 2008, Bay of Bengal (top); 13 July 2008, Tibetan Plateau (middle), and 10 August 2010, Tibetan Plateau (bottom). Continuous lines show the path of CloudSat and parallelograms PR footprints. For PR, the maximum reflectivity in each vertical column of the grid is projected onto the plane. Colour bar on the top refers to $\mathrm{PR} Z_{\mathrm{e}}$ in dBZ units. scans before the point of intersection to 50 scans beyond the point of intersection. These are called coincident overpasses.

CloudSat data collection period is 2 June 2006 to 17 April 2011, and 2D-CloudSat-TRMM dataset spans July 2006 to December 2010, i.e., approximately 4 years and 6 months, providing $\sim 29,000$ coincident overpasses. Figure 1 shows a few examples of PR and CPR coincident overpasses. Because of the difference in their pixel sizes, sampling volumes do not completely overlap. Basically CPR slices through clouds and provides a vertical section along its track, whereas PR captures the three dimensional structure, $\sim 250 \mathrm{~km}$ across. Figure 2 is a pictorial representation of intersection points of CloudSat and TRMM (PR block data). It is seen that the entire latitudinal belt of $38^{\circ} \mathrm{N}-38^{\circ} \mathrm{S}$ is covered more or less uniformly with coincident overpasses.

\subsection{Analysis method}

PR and CPR sampling volumes (footprint sizes in particular) are different and there could be a time delay of up to 50 minutes, thus making one-toone comparison of instantaneous $Z_{\mathrm{e}}$ profiles from these two radars not very meaningful. However, the statistics of their $Z_{\mathrm{e}}$ values can be compared for the coincident overpasses for the following reasons. In most of the results presented here, we include cases where clouds were precipitating by requiring that $\mathrm{PR} Z_{\mathrm{e}} \geq 25 \mathrm{dBZ}$ at least at one vertical level (moderate rain and heavy snow expected, e.g., Houze 1993). As seen from figure 2, oceans dominate the study area where precipitating clouds are normally found in the presence of large scale low level convergence (e.g., Cotton and Anthes 1989) which tends to be a synoptic scale feature. Then major changes in the properties of cloud population within an hour are not expected. Since PR is not sun-synchronous, there is equal probability of PR sampling before and after a CPR pass. Thus, there is no bias in the sampling time difference between PR and CPR coincident passes. Present study uses a large number of coincident overpasses spanning four and half years. Therefore the statistics so obtained is expected to represent average properties of precipitating cloud population in the study region.

In the following, analysis is performed considering two cases:

Case 1: Includes data from coincident passes where both PR and CPR share common sampling volume, i.e., collocated. Further, the PR volume contains $Z_{\mathrm{e}} \geq 25 \mathrm{dBZ}$ at least at one vertical level. 


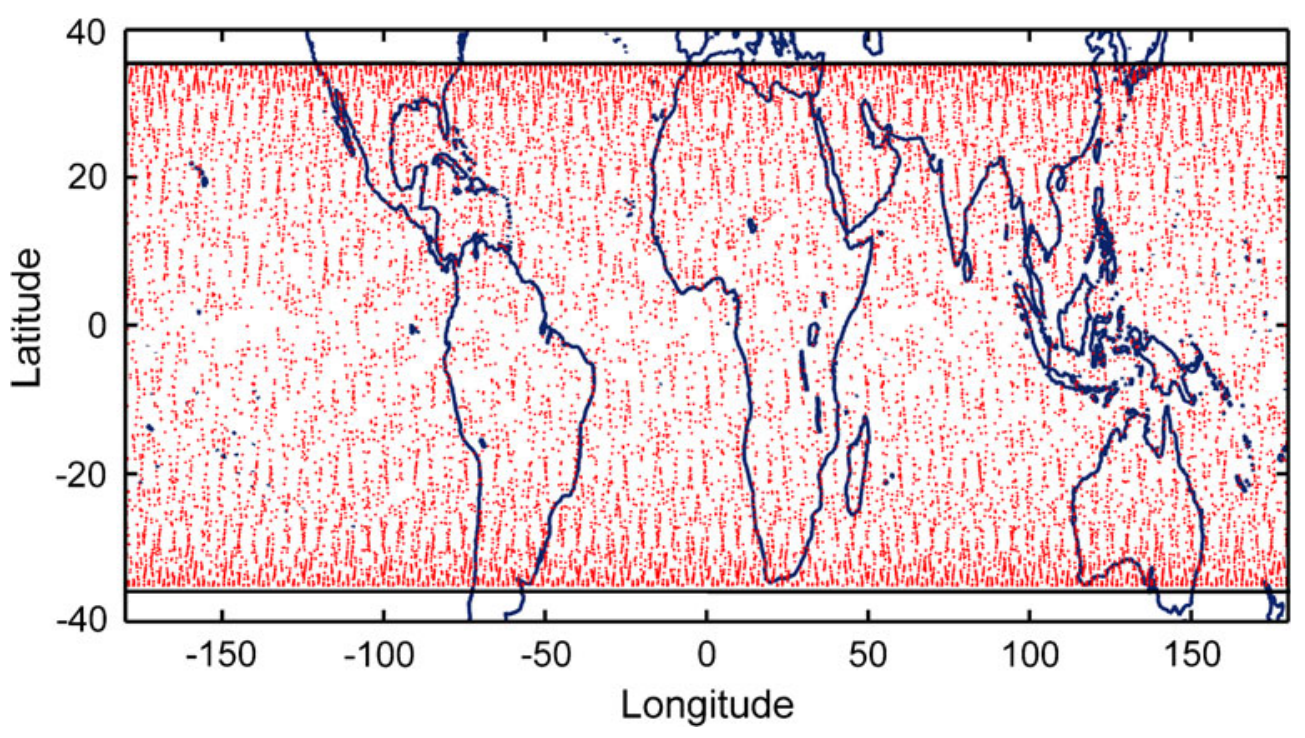

Figure 2. Intersection points of coincident CPR and PR overpasses for the period July 2006 to December 2010.

(a)

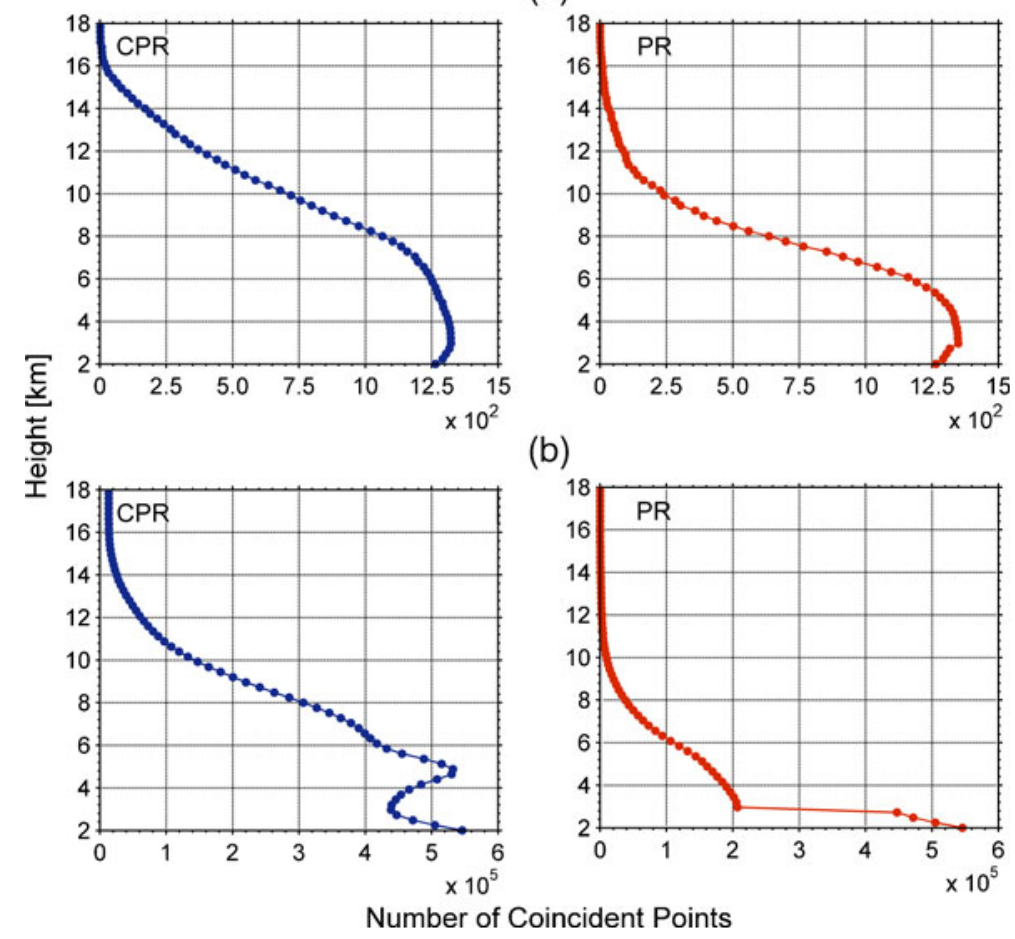

Figure 3. Number of coincident points at different vertical levels for case 1 and case 2 . For case 1 , both CPR and PR show similar trend but not exactly identical owing to the difference in their footprint sizes. Number of coincident points are very few above $15 \mathrm{~km}$. For case 2, CPR shows a peak around the freezing level and at $2 \mathrm{~km}$ height, whereas PR has peak at $2 \mathrm{~km}$ and numbers drop drastically above $10 \mathrm{~km}$.

Case 2: Includes data from grids surrounding the collocated point as well. Thus majority of the volumes are not collocated but both radars sampled the same area near simultaneously. No condition is imposed on magnitude of $Z_{\mathrm{e}}$.
Layer of the atmosphere between 2 and $18 \mathrm{~km}$ altitude range is considered with the lower limit imposed to avoid possible ground contamination, and the upper limit to save computational time since probability of getting valid $Z_{\mathrm{e}}$ is very small above this height (figure 3 ). The contoured 
frequency by altitude diagrams (CFADs) first used by Yuter and Houze (1995) for presenting radar reflectivity data is prepared for both radars as follows. At each height, frequency of occurrence of reflectivity is generated in different bins considering all $Z_{\mathrm{e}}$ profiles belonging to cases 1 and 2 separately. The reflectivity bin size is $5 \mathrm{dBZ}$ and height intervals for CPR and PR are 0.24 and $0.25 \mathrm{~km}$, respectively. The number of cases in a reflectivity bin at each level $k$ is normalized by the total number of cases $\left(N_{\mathrm{k}}\right)$ at that level. Normalized individual histograms are combined and contours of frequency of occurrence are plotted with reflectivity along $\mathrm{x}$-axis and height as ordinate. CFAD provides a method of pictorially representing the vertical variations in cloud systems. This is alright as long as values of $N_{\mathrm{k}}$ at different levels are comparable. However, when the sample number becomes small, the statistics obtained is not representative or robust. In order to avoid the inclusion of cases with small $N_{\mathrm{k}}$, Yuter and Houze (1995) imposed the condition that number $N_{\mathrm{k}}$ should not be less than $10-20 \%$ of $N_{\mathrm{m}}$, where $N_{\mathrm{m}}$ is the maximum value among all $N_{\mathrm{k}} \mathrm{s}$. In the present study, we have set the condition $N_{\mathrm{k}} / N_{\mathrm{m}} \geq 10 \%$, i.e., if $N_{\mathrm{k}}$ is less than $10 \%$ of $N_{\mathrm{m}}$, then level ' $k$ ' data is excluded from CFAD structure.

\section{Results}

Figure 4 shows the CFADs of CPR and PR reflectivities. Horizontal extent at any given height gives the observed range of $Z_{\mathrm{e}}$ and the maximum indicates the most frequently measured value (related to the cloud type) at that height. The most striking feature observed in figure 4(a) is that the peaks in CFADs are distinctly different for CPR and PR so much as it seems that these two radars are sampling different class or populations of clouds. The differences in the horizontal range are far outside the claimed accuracies of $\sim 1-2 \mathrm{dBZ}$ of $\mathrm{CPR}$ and $\mathrm{PR}$ and their modes are separated by more than $10 \mathrm{dBZ}$ below $10 \mathrm{~km}$ height. CPR mode shifts towards lower values of $Z_{\mathrm{e}}$ below $4 \mathrm{~km}$ height whereas PR shows the opposite (figure 5). Nature of the vertical variation of maximum frequency of occurrence is also different (figure 6). CPR has two maxima, one at lower $(\sim 2 \mathrm{~km})$ and another at higher $(\sim 14 \mathrm{~km})$ altitudes. The maximum

(a)
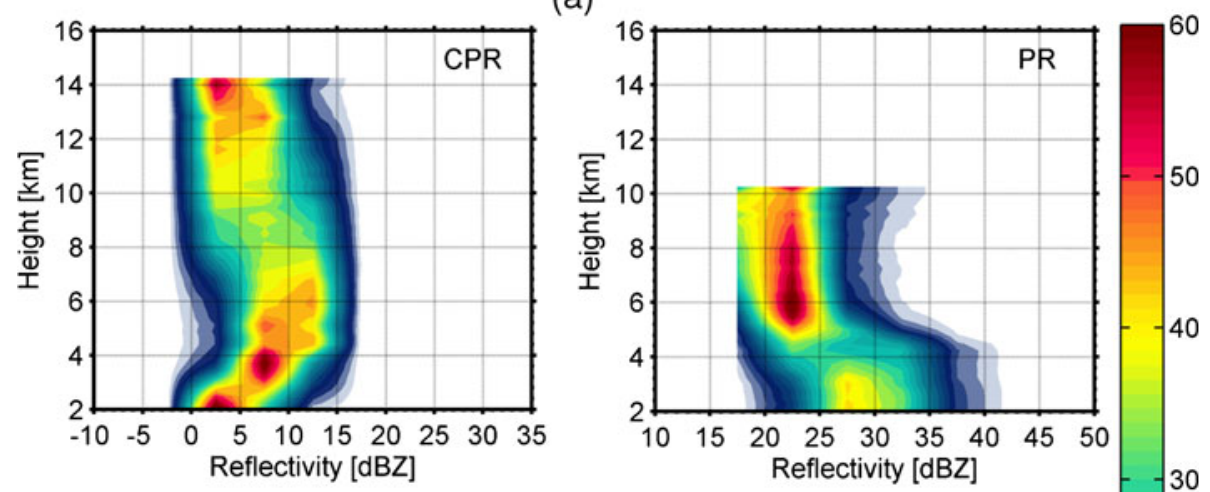

(b)
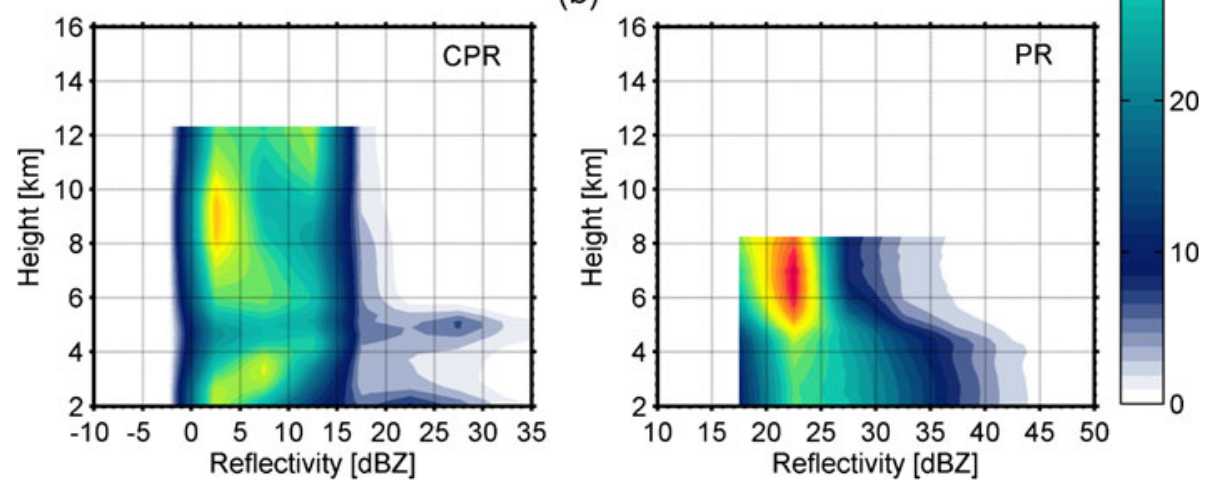

Figure 4. Contoured frequency by altitude diagrams (CFADs) of reflectivities for case 1 (top) and case 2 (bottom). The bin size for $Z_{e}$ is $5 \mathrm{dBZ}$ and height intervals are $0.24 \mathrm{~km}$ and $0.25 \mathrm{~km}$ for CPR and PR respectively. The colour bar shows the frequency (in \%) of reflectivity occurrence. Differences in the maximum height of the contours and abrupt ending are due to the number of points falling below the $10 \%$ criterion used in CFADs (see text for details). The contours' values lower than the minimum detectable limit of $17 \mathrm{dBZ}$ have been cut off in PR CFAD plot. 
frequency at the higher altitude indicates that CPR captures the anvil clouds associated with MCSs, and the other peak is likely to correspond to low level convective clouds (perhaps precipitating cumulus congestus and low level stratus). PR $Z_{\mathrm{e}}$ shows a peak frequency of occurrence between 6 and $7 \mathrm{~km}$ height centred on $Z_{\mathrm{e}}=22.5 \mathrm{dBZ}$ while there is no peak in CPR CFAD in this height range. CFADs of CPR and PR radar reflectivities for case

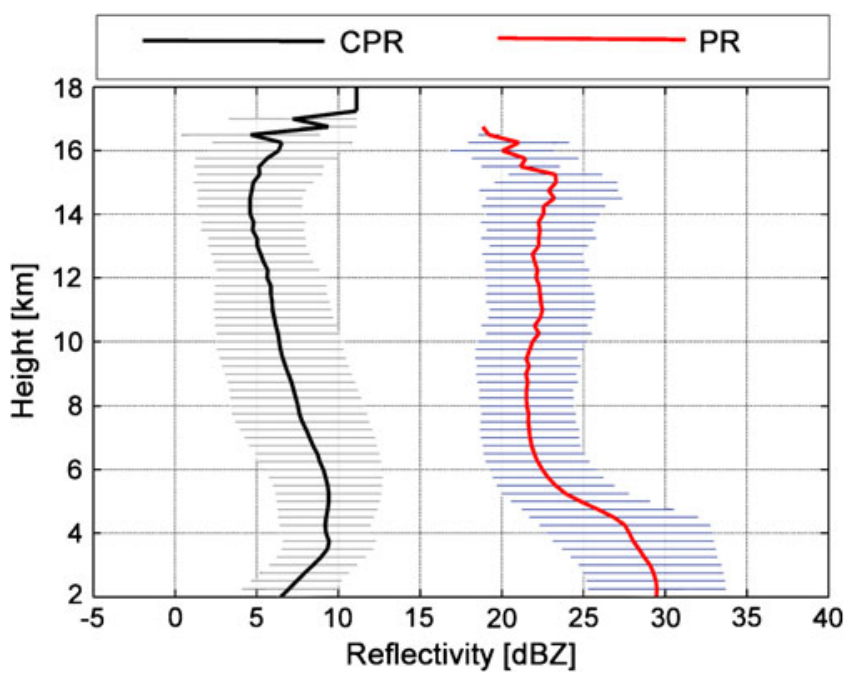

Figure 5. Vertical variation of the mean reflectivity for CPR and PR for case 1 . The error bars correspond to one standard deviation about the mean. At no height, two measurements come close to each other, and mean trends are in opposite directions below $6 \mathrm{~km}$ level.

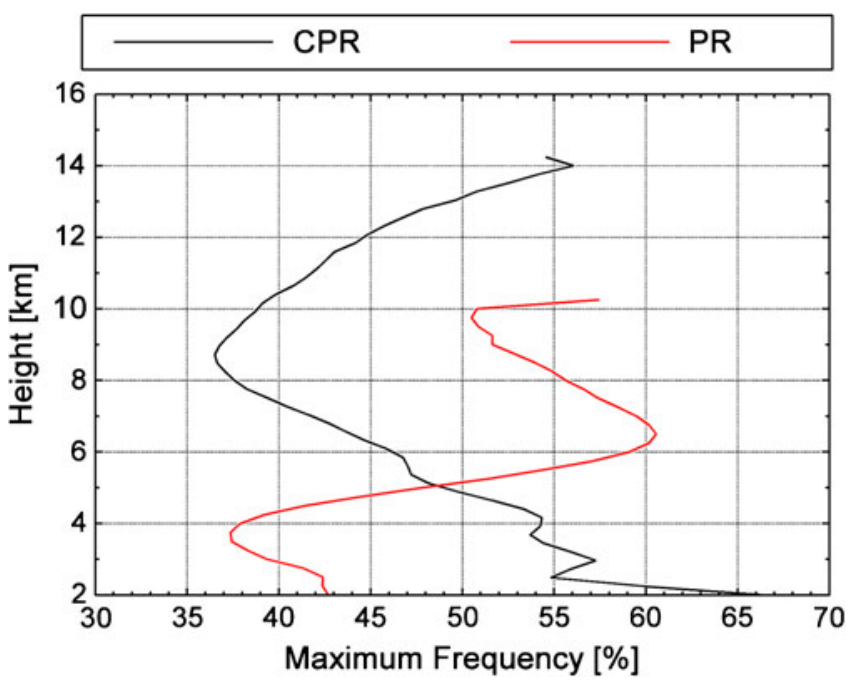

Figure 6. Vertical variation in the maximum frequency of occurrence of CPR and PR reflectivities for case 1 indicating the preference for a certain $Z_{\mathrm{e}}$ to occur more frequently at that height, and the mode itself a function of height as shown in figure 4 .
2 (figure 4b) look different but the main observation made earlier, namely the two radars appear to sample different cloud populations holds good here too. The total area considered in the analysis included tropics and mid-latitudes, and cloud systems may exhibit different vertical variations in cloud hydrometeor properties in these two regions. To explore if the agreement is better in the tropics, analysis was repeated considering the tropics only (i.e., $30^{\circ} \mathrm{S}-30^{\circ} \mathrm{N}$ ). Results more or less reproduced the features observed above and thus the conclusions remain the same for the tropics as well.

Figure 7 shows the frequency distributions of $\mathrm{CPR}$ and $\mathrm{PR}$ reflectivities for case 1 considering all levels between 2 and $18 \mathrm{~km}$. CPR $Z_{\mathrm{e}}$ is slightly negatively skewed whereas $\operatorname{PR~} Z_{\mathrm{e}}$ is positively skewed. The maxima in the reflectivity distributions of CPR and PR are approximately at 9 and $22.5 \mathrm{dBZ}$, respectively. Number of occurrences of $Z_{\mathrm{e}}$ values above $20 \mathrm{dBZ}$ is negligible in $\mathrm{CPR}$ measurements. The measurement range of $\mathrm{CPR}$ is $-30 \mathrm{dBZ}$ to $+40 \mathrm{dBZ}$, while PR $Z$ values start at $\sim 17 \mathrm{dBZ}$. Therefore some overlap of CPR and PR distributions is expected but not seen in figure 7. This suggests that the W-band radar signal gets strongly attenuated in precipitating clouds, especially below $6 \mathrm{~km}$ height where $\mathrm{PR} Z_{\mathrm{e}}$ shows higher values (figure 5). Figure 7 reveals that CPR range ends where PR begins, i.e., PR and CPR cover two ends of precipitating clouds, namely PR measurement capability limited to active precipitating clouds, and CPR more reliable in measuring the spatial extent of cloud systems but not their hydrometeor concentrations (e.g., anvil clouds away from convective core). Combining data from these two radars may lead to more realistic picture

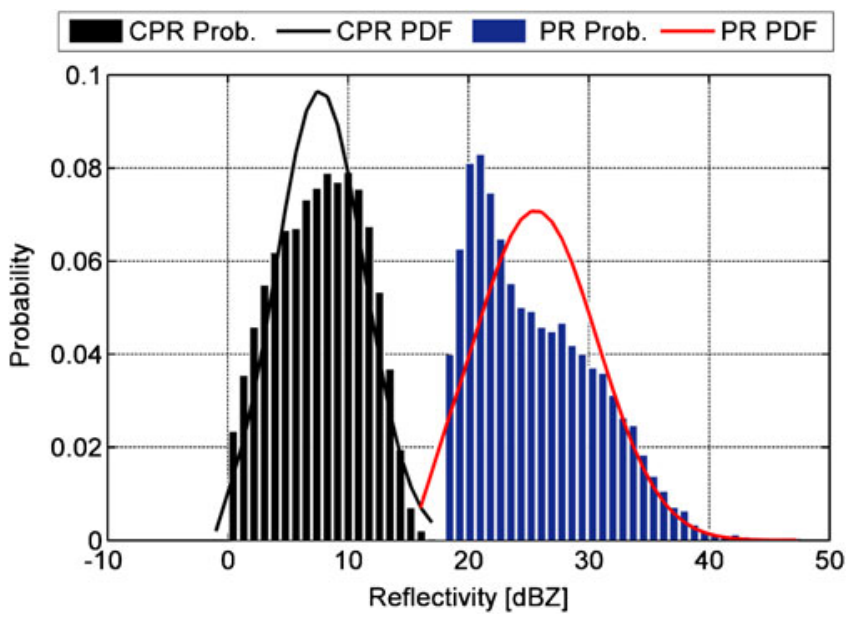

Figure 7. Histograms of the reflectivities for CPR and PR for case 1. Reflectivity values at all heights are taken into consideration while constructing these histograms. Curves (in red and black colours) are the probability density functions obtained by fitting normal distribution function. 

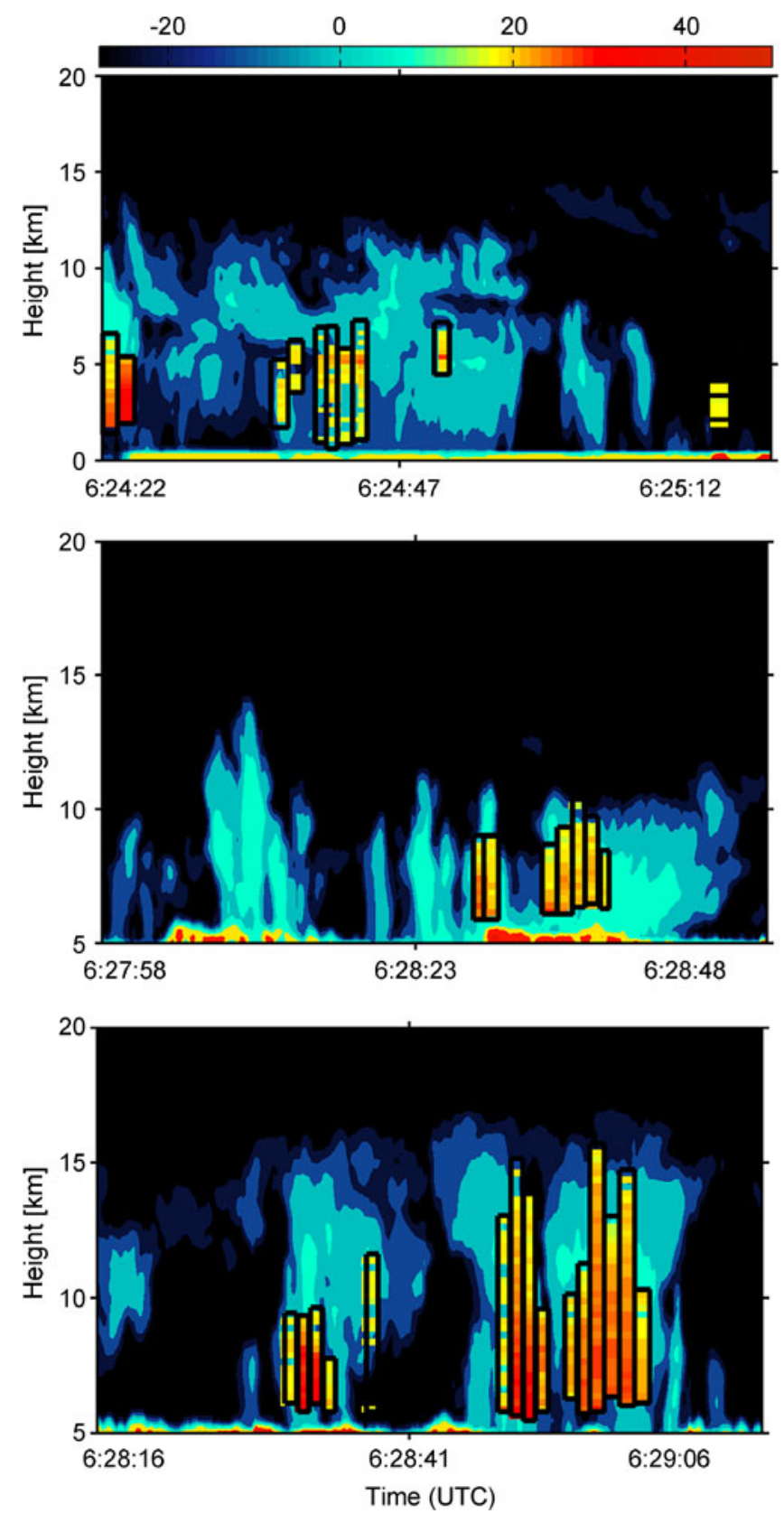

Figure 8. Vertical cross sections of PR $Z_{\mathrm{e}}$ superimposed on that of CPR along the CloudSat path for the cases shown in figure 1 in the same order. Discrete vertical bars and bluish colours correspond to $\mathrm{PR}$ and $\mathrm{CPR}$ reflectivities, respectively. High values at the bottom may be due to surface reflectance (especially over the Tibetan Plateau). The colour bar shows the radar reflectivity values in dBZ units.

of the spatial structure of convective cloud systems. For example, in figure $8, \mathrm{PR}$ curtain reflectivity is superimposed over the CPR curtain reflectivity. In this case, PR data reveals convective towers while the CPR a much extended region of cloudiness. Vertical extent of the cloud systems captured by $\mathrm{CPR}$ is higher than $\mathrm{PR}$ as reported previously ( $\mathrm{Li}$ and Schumacher 2011).

\section{Discussion and conclusions}

It is necessary to have spaceborne radars that provide $3 \mathrm{D}$ measurements of clouds globally. However, they have limitations that need to be kept in mind while drawing conclusions on the cloud characteristics measured by them. Here we have used coincident 2D-CloudSat-TRMM product for comparing the radar reflectivities of CloudSat CPR and TRMM PR radars. PR, essentially meant to measure characteristics of precipitating clouds, misses the anvil part of mesoscale convective systems, and the full spatial extent of MCSs is not covered. CPR captures the cloud spatial coverage better. However, its reflectivity values are much lower due to the strong attenuation suffered by the radar beam operating in W-band. CPR signal gets attenuated severely during rain, more so below $6 \mathrm{~km}$ height. Stephens (1994) attributed this attenuation to 'non-Rayleigh scattering regime' mainly caused by scattering of radar wave by large hydrometeors when their sizes become comparable to or greater than the radar wavelength. Kollias et al. (2007) have reported that the radar signal attenuation is more prominent as radar wave frequency increases. Therefore, although the technical specifications of the two radars indicate that their measurements have common overlap region in 17 to $40 \mathrm{dBZ}$ range, the actual data show very little overlap in their measured $Z$ values. These limitations are to be considered while deriving conclusions on cloud properties from PR and CPR data.

\section{Acknowledgements}

The authors are thankful to CloudSat team, NASA and CloudSat Data Processing Center, NASA for providing the 2D-CloudSat-TRMM product. This work was partially supported by a grant from the Department of Science and Technology, Govt. India New Delhi.

\section{References}

Adeyewa Z D and Nakamura K 2003 Validation of TRMM radar rainfall data over major climatic regions in Africa; J. Appl. Meteorol. 42 331-347.

Barker H W, Korolev A V, Hudak D R, Strapp J W, Strawbridge K B and Wolde M 2008 A comparison between CloudSat and aircraft data for a multilayer, mixed phase cloud system during the Canadian CloudSat-CALIPSO Validation Project; J. Geophys. Res. 113 D00A16, doi: 10.1029/2008JD009971.

Behrangi A, Kuber T and Lambrigtsen B 2012 Phenomenological description of tropical clouds using CloudSat cloud classification; Mon. Weather Rev. 140 3235-3249.

Carty H M and Kuo K S 2008 A report: 2D-CloudSatTRMM product description version 1.0; CloudSat Project, A NASA Earth system pathfinder mission. 
Casey S P F, Dessler A E and Schumacher C 2007 Frequency of tropical precipitating clouds as observed by the Tropical Rainfall Measuring Mission precipitation radar and ICESat/Geoscience laser altimeter system; J. Geophys. Res. 112 D14215, doi: 10.1029/2007JD008468.

Casey S P F, Fetzer E J and Kahn B H 2012 Revised identification of tropical oceanic cumulus congestus as viewed by CloudSat; Atmos. Chem. Phys. 12 1587-1595.

Cetrone J and Houze Jr R A 2009 Anvil clouds of tropical mesoscale convective systems in monsoon regions; Quart. J. Roy. Meteorol. Soc. 135 305-317.

Charney J G 1969 The intertropical convergence zone and the Hadley circulation of the atmosphere; Proc. WMO/IUGG Symposium on Numerical Weather Prediction, Tokyo, Japan, pp. III-73-79.

CIMO 2008 Guide to Meteorological Instruments and Methods of Observation; Secretariat of the WMO. Part II Observing methods. WMO No. 8, 7th edn, pp. II.9-6-12.

Cotton W R and Anthes R A 1989 Storm and cloud dynamics; Chapter 6, Academic Press, New York, p. 882.

Diner D J, Beckert J C, Reilly T H, Bruegge C J, Conel J E, Kahn R A, Martonchik J V, Ackerman T P, Davies R, Gerstl S A W, Gordon H R, Muller J P, Myneni R B, Sellers P J, Pinty B and Verstraete M M 1998 Multi-angle Imaging SpectroRadiometer (MISR) instrument description and experiment overview; IEEE Trans. Geosci. Remote Sens. 36 1072-1087.

Dinku T, Ruiz F, Connor S J and Ceccato P 2010 Validation and intercomparison of satellite rainfall estimates over Colombia; J. Appl. Meteorol. Climatol. 49 1004-1014.

Franchito S H, Rao V B, Vasques A C, Santo C M E and Conforte J C 2009 Validation of TRMM precipitation radar monthly rainfall estimates over Brazil; J. Geophys. Res. 114 D02105, doi: 10.1029/2007JD009580.

Gorgucci E and Chandrasekar V 2005 Evaluation of attenuation correction methodology for dual-polarization radars: Application to X-Band systems; J. Atmos. Ocean. Tech. 22 1195-1206.

Gourley J J, Hong Y, Flmaig Z L, Li L and Wang J 2010 Intercomparison of rainfall estimates from radar, satellite, gauge, and combinations for a season of record rainfall; J. Appl. Meteorol. Climatol. 49 437-452.

Haynes J M and Stephens G L 2007 Tropical oceanic cloudiness and the incidence of precipitation early results from CloudSat; Geophys. Res. Lett. 34 L09811, doi: 10.1029/2007GL029335

Hence D A and Houze Jr R A 2011 Vertical structure of tropical cyclones with concentric eyewalls as seen by the TRMM precipitation radar; J. Atmos. Sci. 69 1021-1036.

Holton J R 2004 An introduction to dynamic meteorology; Chapter 11; 4th edn, Elsevier Academic Press, New York, p. 531.

Houze Jr R A 1993 Cloud Dynamics. Academic Press, San Diego, pp. 112-114.

Hudak D, Rodriguez P and Donaldson N 2008 Validation of the CloudSat precipitation occurrence algorithm using the Canadian C-band radar network; J. Geophys. Res. 113. D00A07, doi: 10.1029/2008JD009992.

Iguchi T and Meneghini R 1994 Intercomparison of single frequency methods for retrieving a vertical rain profile from airborne or space borne data; J. Atmos. Ocean. Tech. 11 1507-1516.

Kawanishi T, Kuroiwa H, Kojima M, Oikawa K, Kozu T, Kumagai H, Okamoto K, Okumura M, Nakatsuka H and Nishikawa K 2000 TRMM Precipitation Radar; Adv. Spac. Res. 25 969-972.

Kerr R A 2009 Clouds appear to be big, bad player in global warming; Science $\mathbf{3 2 5} 376$.
Kim S W, Chung E S, Yoon S C, Sohn B J and Sugimoto N 2011 Intercomparisons of cloud-top and cloud-base heights from ground-based Lidar, CloudSat and CALIPSO measurements; Int. J. Rem. Sens. 32 $1179-1197$.

King M D, Kaufman Y J, Menzel W P and Tanré D 1992 Remote sensing of cloud, aerosol, and water vapor properties from the moderate resolution imaging spectrometer (MODIS); IEEE Trans. Geosci. Rem. Sens. 30 $2-27$.

Kollias P, Clothiaux E E, Miller M A, Albrecht B A, Stephens G L and Ackerman T P 2007 MillimeterWavelength Radars: New frontier in atmospheric cloud and precipitation research; Bull. Am. Meteorol. Soc. 88 1608-1624.

Kummerow C, Barnes W, Kozu T, Shiue J and Simpson J 1998 The tropical rainfall measuring mission (TRMM) sensor package; J. Atmos. Ocean. Tech. 15 809-817.

Kummerow C, Simpson J, Thiele O, Barnes W, Chang A T C, Stocker E, Adler R F, Hou A, Kakar R, Wentz F, Ashcroft P, Kozu T, Hong Y, Okamoto K, Iguchi T, Kuroiwa H, Im E, Haddad Z, Huffman G, Ferrier B, Olson W S, Zipser E, Smith E A, Wilheit T T, North G, Krishnamurti T N and Nakamura K 2000 The status of the Tropical Rainfall Measuring Mission (TRMM) after two years in orbit; J. Appl. Meteorol. 39 1965-1982.

Li W and Schumacher C 2011 Thick anvils as viewed by the TRMM precipitation radar; J. Climate 24 1718-1735.

Liu C and Zipser E J 2008 Diurnal cycles of precipitation, clouds, and lightning in the tropics from 9 years of TRMM observations; Geophys. Res. Lett. 35 L04819, doi: 10.1029/2007GL032437.

Luo Z, Liu G Y and Stephens G L 2008 CloudSat adding new insight into tropical penetrating convection; Geophys. Res. Lett. 35 L19819, doi: 10.1029/2008GL035330.

Mace G G, Marchand R, Zhang Q and Stephens G L 2007 Global hydrometeor occurrence as observed by CloudSat initial observations from summer 2006; Geophys. Res. Lett. 34 L09808, doi: 10.1029/2006GL029017.

Marchand R T, Mace G, Ackerman T and Stephens G L 2008 Hydrometeor detection using CloudSat - an earth orbiting $94 \mathrm{GHz}$ cloud radar; J. Atmos. Ocean. Tech. 25 $519-533$

Masunga H and Kummerow C D 2006 Observations of tropical precipitating clouds ranging from shallow to deep convective systems; Geophys. Res. Lett. 33 L16805, doi: 10.1029/2006GL026547.

Nair S, Srinivasan G and Nemani R 2009 Evaluation of multi-satellite TRMM derived rainfall estimates over a western state of India; J. Meteorol. Soc. Japan $\mathbf{8 7}$ 927-939.

Nicholson S E, Some B, Mccollum J, Nelkin E, Klotter D, Berte Y, Diallo B M, Gaye I, Kpabeba G, Ndiaye O, Noukpozounkou J N, Tanu M M, Thiam A, Toure A A and Traore A K 2003a Validation of TRMM and other rainfall estimates with a high-density gauge dataset for west Africa. Part I: Validation of GPCC rainfall product and pre-TRMM satellite and blended products; J. Appl. Meteorol. 42 1337-1354.

Nicholson S E, Some B, Mccollum J, Nelkin E, Klotter D, Berte Y, Diallo B M, Gaye I, Kpabeba G, Ndiaye O, Noukpozounkou J N, Tanu M M, Thiam A, Toure A A and Traore A K 2003b Validation of TRMM and other rainfall estimates with a high-density gauge dataset for west Africa. Part II: Validation of TRMM rainfall products; J. Appl. Meteorol. 42 1355-1368.

Protat A, Bouniol D, O'Connor E J, Baltink H K, Verlinde $\mathrm{J}$ and Widener K 2011 CloudSat as a global calibrator; J. Atmos. Ocean. Tech. 28 445-452. 
Rajeevan M, Rohni P, Kumar K N, Srinivasan J and Unnikrishnan C K 2012 A study of vertical cloud structure of the Indian summer monsoon using CloudSat data; Clim. Dynam. 40 637-650.

Randall D, Wood R, Bony S, Colman R, Fichefet T, Fyfe J, Kattsov V, Pitman A, Shukla J, Srinivasan J, Stouffer R, Sumi A and Tayler K 2007 Climate models and their evaluation; In: Climate Change 200\%: The Scientific Basis. Contribution of working group I to the Forth Assessment Report of the Inter-governmental Panel on Climate Change (eds) Solomon S, Qin D, Manning M, Chen Z, Marquis M, Averyt K B, Tignor $M$ and Miller H L, Cambridge Univ. Press, Cambridge, United Kingdom, pp. 589-662.

Schmetz J, Pili P, Tjemkes S, Just D, Kerkmann J, Rota S and Ratier A 2002 An introduction to Meteosat second generation (MSG); Bull. Am. Meteorol. Soc. 83 977-992.

Schumacher C and Houze Jr R A 2000 Comparison of radar data from the TRMM satellite and Kwajalein oceanic validation site; J. Appl. Meteorol. 39 2151-2164.

Schumacher C and Houze Jr R A 2006 Stratiform precipitation production over sub-Saharan Africa and the tropical East Atlantic as observed by TRMM; Quart. J. Roy. Meteorol. Soc. 132 2235-2255.

Steiner M and Houze Jr R A 1998 Sensitivity of monthly three-dimensional radar-echo characteristics to sampling frequency; J. Meteorol. Soc. Japan 76 73-95.

Stephens G L 1994 Remote sensing of the lower atmosphere: An introduction; Oxford University Press, UK, 523p.

Stephens G L, Vane D G, Boain R J, Mace G G, Sassen K, Wang Z, Illingworth A J, O'Connor E, Rossow W B, Durden S L, Miler S D, Austin R T, Benedetti A, Mitrescu $\mathrm{C}$ and CloudSat Science Team 2002 The CloudSat mission and the A-TRAIN: A new dimension to spacebased observations of clouds and precipitation; Bull. Am. Meteorol. Soc. 83 1771-1790.
Stephens G L, Vane D G, Tanelli S, Im E, Durden S, Rokey M, Reinke D, Partain P, Mace G G, Austin R, L'Ecuyer T, Haynes J, Lebsock M, Suzuki K, Waliser D, Wu D, Kay J, Gettelman A, Wang Z and Marchand R 2008 CloudSat mission performance and early science after first year of operation; J. Geophys. Res. 113 D00A18, doi: 10.1029/2008JD009982.

Testud J, Bouar E L, Obligis E and Ali-Mehenni M 2000 The rain profiling algorithm applied to polarimetric weather radar; J. Atmos. Ocean. Tech. 17 332-356.

Wielicki B A, Barkstrom B R, Harrison E F, Lee R B, Smith G L and Cooper J E 1996 Clouds and the earth's radiant energy system (CERES). An earth observing system experiment; Bull. Am. Meteorol. Soc. $77853-868$.

Winker D M, Vaughan M A, Omar A, Hu Y, Powell K A, Liu Z, Hunt W H and Young S A 2009 Overview of the CALIPSO Mission and CALIOP data processing algorithms; J. Atmos. Ocean. Tech. 26 2310-2323.

Wolff D B, Marks D A, Amitai E, Silberstein D S, Fisher B L, Tokay A, Wang J and Pippitt J L 2005 Ground validation for the Tropical Rainfall Measuring Mission (TRMM); J. Atmos. Ocean. Tech. 22 365-380.

Yuan J, Houze Jr R A and Heymsfield A 2011 Vertical structures of anvil clouds of tropical mesoscale convective systems observed by CloudSat; J. Atmos. Sci. 68 1653-1674.

Yuter S E and Houze Jr R A 1995 Three-dimensional kinematic and microphysical evolution of Florida cumulonimbus. Part II: Frequency distribution of vertical velocity, reflectivity, and differential reflectivity; Mon. Weather Rev. 123 1941-1963.

Zhang Y, Klein S, Mace G G and Boyle J 2007 Cluster analysis of tropical clouds using CloudSat data; Geophys. Res. Lett. 34 L12813, doi: 10.1029/2007GL029336. 